\title{
Silver/poly (lactic acid) nanocomposites: preparation, characterization, and antibacterial activity
}

This article was published in the following Dove Press journal:

International Journal of Nanomedicine

5 August 2010

Number of times this article has been viewed

\author{
Kamyar Shameli' \\ Mansor Bin Ahmad' \\ Wan Md Zin Wan Yunus' \\ Nor Azowa Ibrahim' \\ Russly Abdul Rahman ${ }^{2}$ \\ Maryam Jokar ${ }^{2,3}$ \\ Majid Darroudi ${ }^{4}$ \\ 'Department of Chemistry, Faculty \\ of Science, Universiti Putra Malaysia, \\ Selangor, Malaysia; ${ }^{2}$ Department of \\ Food Technology, Faculty of Food \\ Science and Technology, Universiti \\ Putra Malaysia, Selangor, Malaysia; \\ ${ }^{3}$ Department of Food Technology, \\ Islamic Azad University, Damghan \\ Branch, Damghan, Iran; ${ }^{4}$ Advanced \\ Materials and Nanotechnology \\ Laboratory, Institute of Advanced \\ Technology (ITMA), Universiti Putra \\ Malaysia, Selangor, Malaysia
}

\begin{abstract}
In this study, antibacterial characteristic of silver/poly (lactic acid) nanocomposite (Ag/PLA-NC) films was investigated, while silver nanoparticles (Ag-NPs) were synthesized into biodegradable PLA via chemical reduction method in diphase solvent. Silver nitrate and sodium borohydride were respectively used as a silver precursor and reducing agent in the PLA, which acted as a polymeric matrix and stabilizer. Meanwhile, the properties of $\mathrm{Ag} / \mathrm{PLA}-\mathrm{NCs}$ were studied as a function of the Ag-NP weight percentages $(8,16$, and $32 \mathrm{wt} \%$ respectively), in relation to the use of PLA. The morphology of the Ag/PLA-NC films and the distribution of the Ag-NPs were also characterized. The silver ions released from the $\mathrm{Ag} / \mathrm{PLA}-\mathrm{NC}$ films and their antibacterial activities were scrutinized. The antibacterial activities of the Ag/PLA-NC films were examined against Gram-negative bacteria (Escherichia coli and Vibrio parahaemolyticus) and Gram-positive bacteria (Staphylococcus aureus) by diffusion method using Muller-Hinton agar. The results indicated that Ag/PLA-NC films possessed a strong antibacterial activity with the increase in the percentage of Ag-NPs in the PLA. Thus, Ag/PLA-NC films can be used as an antibacterial scaffold for tissue engineering and medical application.
\end{abstract}

Keywords: antibacterial activity, silver nanoparticles, biodegradable, poly (lactic acid), MullerHinton agar

\section{Introduction}

Biocompatible and biodegradable polymers became very important and gained a lot of attention from both biomedical and ecological outlooks in the past decade. ${ }^{1}$ At that time, synthetic biodegradable polymers were given a lot of attention because they could be used in important biomedical applications approved by the US Food and Drug Administration. Among the most popular and important biodegradable polymers are aliphatic polyesters ${ }^{2-5}$ such as poly (3-hydroxybutyrate), poly ( $\varepsilon$-caprolactone), poly (glycolic acid), and poly (lactic acid) (PLA), whereby PLA received the most attention due to its renewable resources, ${ }^{6}$ biodegradation, biocompatibility, as well as excellent thermal and mechanical properties, and superior transparency of the processed materials. ${ }^{7}$ Moreover, PLA is widely used in various medical applications such as surgical implants, tissue culture, resorbable surgical sutures, wound closure, and controlled release systems. ${ }^{2-5}$ PLA produced from renewable resources is a linear aliphatic thermoplastic, which is readily biodegradable through hydrolytic and enzymatic pathways. ${ }^{8-10}$ More importantly, PLA is an immunologically inert synthetic polymer, ${ }^{11,12}$ and for this reason, it was chosen for designing a composition of tissue engineering scaffold in the present study. ${ }^{13,14}$
Correspondence: Kamyar Shameli Department of Chemistry, Faculty of Science, Universiti Putra Malaysia, 43400 UPM Serdang,

Selangor, Malaysia

Tel +60389466793

Fax +60389435380

Email kamyarshameli@gmail.com 
As they possess strong antibacterial properties and low toxicity, silver nanoparticles (Ag-NPs) and their compounds have been studied for many years not only for their low toxicity, but also for their antibacterial activity. ${ }^{15-18}$ Yeo et al found that fibers containing silver showed excellent antibacterial properties. ${ }^{19}$ Meanwhile, studies conducted on Ag-NPs using different polymers have been reported; these include the synthesis in poly vinyl pyrrolidone, ${ }^{20}$ poly (vinyl alcohol), ${ }^{21}$ hyper branched polyurethane $e^{22}$ and poly acrylonitrile ${ }^{23}$ to give discrete Ag-NPs. There are significant variations in the average sizes and shapes of the Ag-NPs when the polymers were used due to the different chemical structures and Ag/polymer interactions. Natural polymers have also attracted great interest, because they are biocompatible and non-toxic in most cases. Among the few stabilizers or matrices investigated for metal nanoparticles are chitosan, ${ }^{24}$ starch, ${ }^{25}$ cellulose, ${ }^{26}$ and natural rubber. ${ }^{27}$

In this work, Ag/PLA-NC films were synthesized using $\mathrm{AgNO}_{3}$ and sodium borohydride as silver precursor and reduction agent respectively in the PLA as a polymeric matrix in the diphase solvent. The antibacterial activity of the Ag/PLA-NCs was also determined.

\section{Materials and methods Materials}

All reagents in this work were of analytical grades and used in their original form without any purification; in particular, PLA (density: $1.24 \mathrm{~g} / \mathrm{mL},>98 \%$ ), which was supplied by Nature Works 4060D (USA). $\mathrm{AgNO}_{3}(99.98 \%$ ) and $\mathrm{NaBH}_{4}(98.5 \%)$ were obtained from Sigma-Aldrich (USA). N, N-dimethyl formamide (DMF) (99.0\%) and dichloromethane (99.0\%) were purchased from Merck (Germany). Phosphate buffer saline (PBS) $(\mathrm{pH}=7.00)$ was supplied by JT Baker (Germany). All the aqueous solutions were made using double distilled water (DD-water).

\section{Synthesis of Ag/PLA-NCs by using $\mathrm{NaBH}_{4}$}

PLA was dissolved in a mixed solvent of $\mathrm{DMF}$ and $\mathrm{CH}_{2} \mathrm{Cl}_{2}$ $(1 / 9 \mathrm{v} / \mathrm{v})$ to achieve a concentration of $10 \mathrm{wt} \%$, and certain amounts of $\mathrm{AgNO}_{3}(0.8,1.6$, and $3.2 \mathrm{~g})$ were added to the solution. The $\mathrm{AgNO}_{3} / \mathrm{PLA}$ solution was observed to be colorless when stirred for 48 hours in an ice water bath, and then $10 \mathrm{~mL}$ of $\mathrm{NaBH}_{4}$ aqueous solution (molar ratio of $\mathrm{AgNO}_{3} / \mathrm{NaBH}_{4}$ was 1:2) was added dropwise into $\mathrm{AgNO}_{3} / \mathrm{PLA}$ solution under vigorous stirring at the same temperature for 2 hours. The formation of the Ag-NPs started in the aqueous phase, but later the nanoparticles transferred to the organic phase due to the presence of van der Waals interactions between the hydroxyl groups of the PLA and the partial charges surrounded in the surface of the Ag-NPs. ${ }^{28,29}$ The organic phase containing stable Ag-NP colloid was separated from the aqueous phase and shaken with DD-water twice to remove any silver ions. After drying at room temperature, the $\mathrm{Ag} / \mathrm{PLA}-\mathrm{NC}$ films were dissolved in $\mathrm{CH}_{2} \mathrm{Cl}_{2}$ and dried using solution-casting technique after ultrasonication for 15 minutes.

\section{Silver ions release}

For determination of silver ions release, the Ag/PLA-NC films were cut into $(1.0 \mathrm{~cm} \times 1.0 \mathrm{~cm})$ pieces with approximately $3.0 \mathrm{mg}$ in weight. The in vitro release of silver was carried out in $10 \mathrm{~mL}$ of PBS. The samples were incubated at $37^{\circ} \mathrm{C}$ under water shaker at $70 \mathrm{rev} \mathrm{min}^{-1}$. The concentration of silver in the solution withdrawn from the test medium at the fixed time intervals was determined using atomic absorption spectroscopy.

\section{Evolution of antibacterial activity}

In vitro antibacterial activity of the samples was evaluated using disc diffusion method with Muller-Hinton agar and a determination of inhibition zone in millimeters ( $\mathrm{mm}$ ) which conforms to the recommended standards of the National Committee for Clinical Laboratory Standards. The antibacterial activity of Ag/PLA-NC films was scrutinized against Gram-negative bacteria, Escherichia coli ATCC 13706 and Vibrio parahaemolyticus ATCC 17802, and Gram-positive bacteria, Staphylococcus aureus ATCC 12600, at different percentages of Ag-NPs in the polymeric matrix. In order to recover the lyophilized culture, the desired culture contained in the plastic bead was aseptically transferred into a tube containing $5 \mathrm{~mL}$ of nutrient broth and maintained in an incubator at $37^{\circ} \mathrm{C}$ for 24 hours for bacteria and $25^{\circ} \mathrm{C}$ for 72 hours for mold. The working stock cultures were maintained on the tripton soy agar (TSA) and potato dextrose agar (Oxoid Ltd, England) slants for the bacteria and mold, respectively, at $4^{\circ} \mathrm{C}$ in a refrigerator. A single bacterial colony for each microorganism was used to inoculate $100 \mathrm{~mL}$ sterile tripton soy broth, which was grown aerobically overnight at $37^{\circ} \mathrm{C}$ in a rotary shaker at

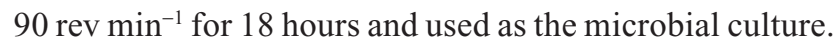
The initial concentration of the cultures was $4.48 \times 10^{7}$ for $E$. coli, $7.61 \times 10^{6}$ for $S$. aureus, and $7.24 \times 10^{6}$ for $V$. parahaemolyticus, and these were determined using the solid agar plate test. Square samples $(1.5 \times 1.5 \mathrm{~cm})$ of PLA and $\mathrm{Ag} / \mathrm{PLA}-\mathrm{NC}$ films containing different percentages of 
Ag-NPs were sterilized by dipping them in ethanol alcohol for 15 minutes and placed on the surface of TSA which was seeded by $1.0 \mathrm{~mL}$ of microorganism culture. The plates were inoculated at $37^{\circ} \mathrm{C}$ for 24 hours. The diameters of the inhibition zone around the film specimen were used to determine the antimicrobial activity of each film sample, and the average of 3 replications was recorded.

\section{Characterization methods and instrumental}

The synthesis of nano Ag/PLA was characterized using $\mathrm{X}$-ray diffraction (XRD), transmission electron microscopy (TEM), UV-visible (UV-vis) spectroscopy, Fourier transform infrared (FT-IR) spectroscopy, and atomic absorption spectrometer. Meanwhile, the structure of the Ag/PLA produced was studied using the XRD (Philips, X'pert, $\mathrm{Cu} \mathrm{Ka}$ ) and were recorded at a scan speed of $4 \% \mathrm{~min}$. The TEM observations were carried out using a Hitachi H-7100 electron microscope, whereas the particle size distributions were determined using the UTHSCSA Image Tool version 3.00 program. The UV-vis spectra were recorded over a range of 300-700 $\mathrm{nm}$ with an H.UV.1650PC (SHIMADZU).B UV-vis spectrophotometer. FT-IR spectra were recorded over the range of $400-4000 \mathrm{~cm}^{-1}$ with a Perkin Elmer 1650, FT-IR spectrophotometer. The released $\mathrm{Ag}^{+}$concentration in the PBS solution was determined using the atomic absorption spectrometer (Thermo Scientific, S. Series).

\section{Results and discussion X-ray diffraction}

The XRD patterns of PLA and Ag/PLA-NCs are shown in Figure 1. In addition to the broad diffraction peak, which was centered at $16.25^{\circ}$ and could be assigned to PLA, 5 crystalline peaks were observed at $2 \theta^{\circ}$ of $38.18^{\circ}, 44.3^{\circ}$, $64.55^{\circ}, 77.54^{\circ}$, and $81.71^{\circ}$. Their intensities were found to be markedly enhanced with the increasing Ag-NP content in the polymeric matrix. In more specific, they were attributed to the $111,200,220,311$, and 222 crystallographic planes of face-centered cubic (fcc) silver crystals, respectively ${ }^{30}$ (XRD ref no 01-087-0718). The XRD peaks broadenings of Ag-NPs (8, 16, and $32 \mathrm{wt} \%$ respectively) were mostly because of the existing nanosized particles in the nanocomposites. ${ }^{31}$ Based on the information presented in Figure 1, five silver crystalline peak intensities were also found to increase with the increase in the percentage of Ag-NPs in PLA. This implies that the Ag-NPs existed in the surface and inside of PLA sheets.

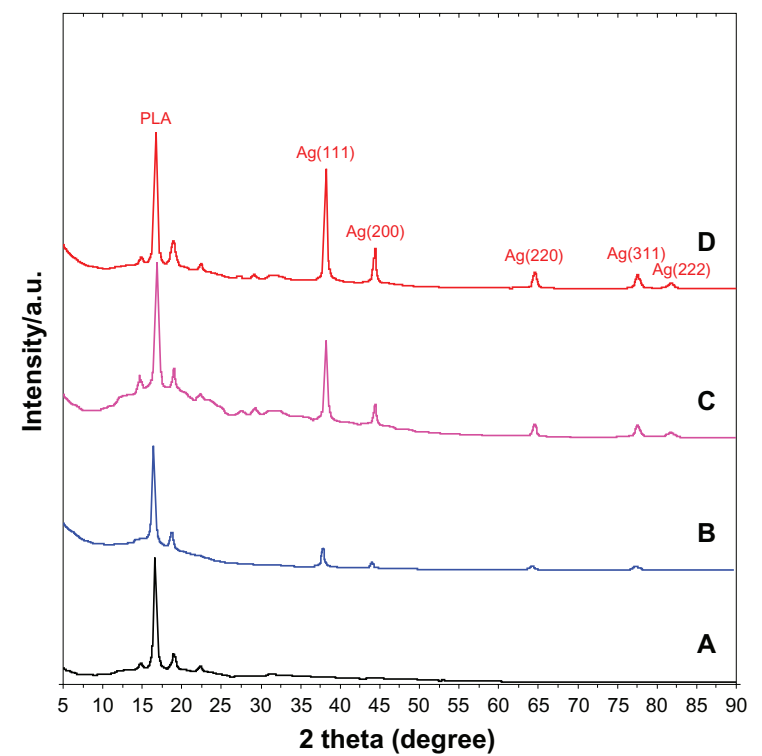

Figure I X-ray diffraction patterns of PLA (A), 8 (B), 16 (C), 32 (D) wt\% of Ag/ PLA-NCs.

Abbreviations: PLA, poly (lactic acid); NC, nanocomposite.

\section{UV-visible spectroscopy}

After adding reducing agent, the color of the solution turned light brown, brown, and dark brown. The generation of Ag-NPs could be identified from the UV-vis spectra. The characteristic of the silver SPR bands was detected to be around $400 \mathrm{~nm}$. These absorption bands were presumably corresponding to the Ag-NPs smaller than $10 \mathrm{~nm} .^{32,33}$ Nonetheless, there is no characteristic UV-vis absorption of Ag-NPs before adding $\mathrm{NaBH}_{4}$ into $\mathrm{AgNO}_{3} / \mathrm{PLA}$ (Figure 2a),

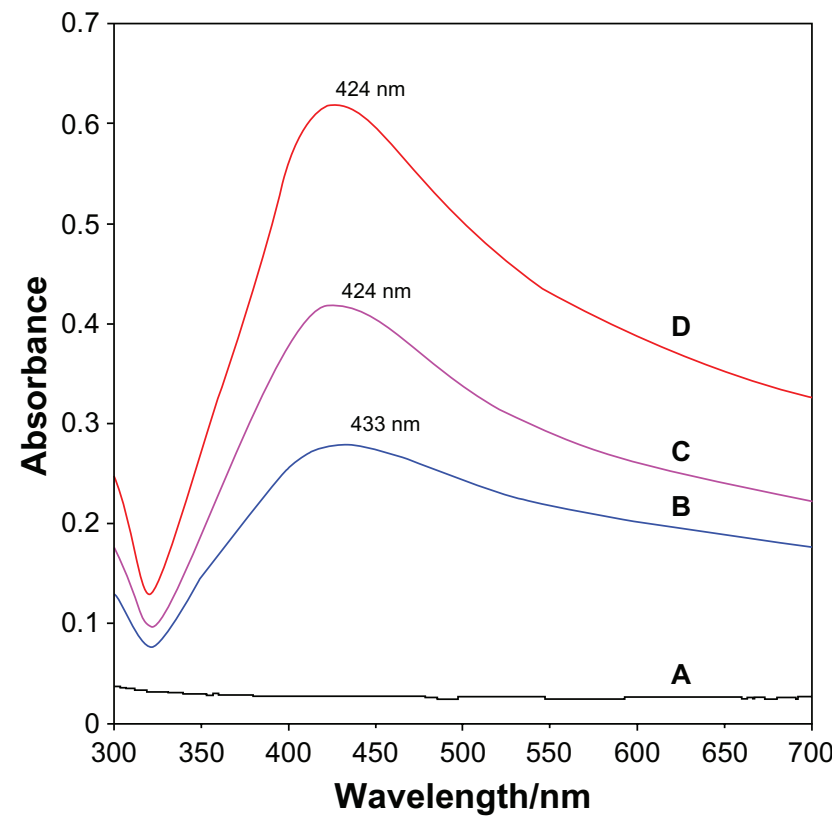

Figure 2 UV-visible spectra of PLA (A), 8 (B), 16 (C), 32 (D) wt\% of Ag/PLA-NCs. Abbreviations: PLA, poly (lactic acid); NC, nanocomposite. 
while the growth of the Plasmon peak at $433 \mathrm{~nm}$ indicates the formation of Ag-NPs (Figure 2a). With the increase in Ag-NP concentration, the corresponding peak intensities in a range of wavelengths from $424-433 \mathrm{~nm}$ increases. The absorption peaks for the 16 and $32 \mathrm{wt} \%$ of Ag-NPs (Figures $2 \mathrm{c}$ and $2 \mathrm{~d}$ ) are slightly shifted to the lower wavelength $(424 \mathrm{~nm})$ indicating that mean diameters of Ag-NPs are different. ${ }^{21,34}$

\section{Morphology}

Figure 3 demonstrates TEM and size distribution of Ag/PLA-NC film containing different amounts of Ag-NPs.
TEM image and their size distribution show that the mean diameters and standard deviation of Ag-NPs (8, 16, and $32 \mathrm{wt} \%$ relative to PLA) are $3.27 \pm 0.74,3.83 \pm 0.85$, and $4.77 \pm 1.15 \mathrm{~nm}$ respectively. Furthermore, this confirms the uniform distribution of the Ag-NPs in the PLA matrix, although particles seem to aggregate to some extent. The observation could be attributed to a strong interaction between $\mathrm{AgNO}_{3}$ and PLA molecular chains, which promoted phase separation of polymer, thus preventing Ag-NPs from coagulating in the reduction process. TEM images show that with the increased percentages of Ag-NPs in the
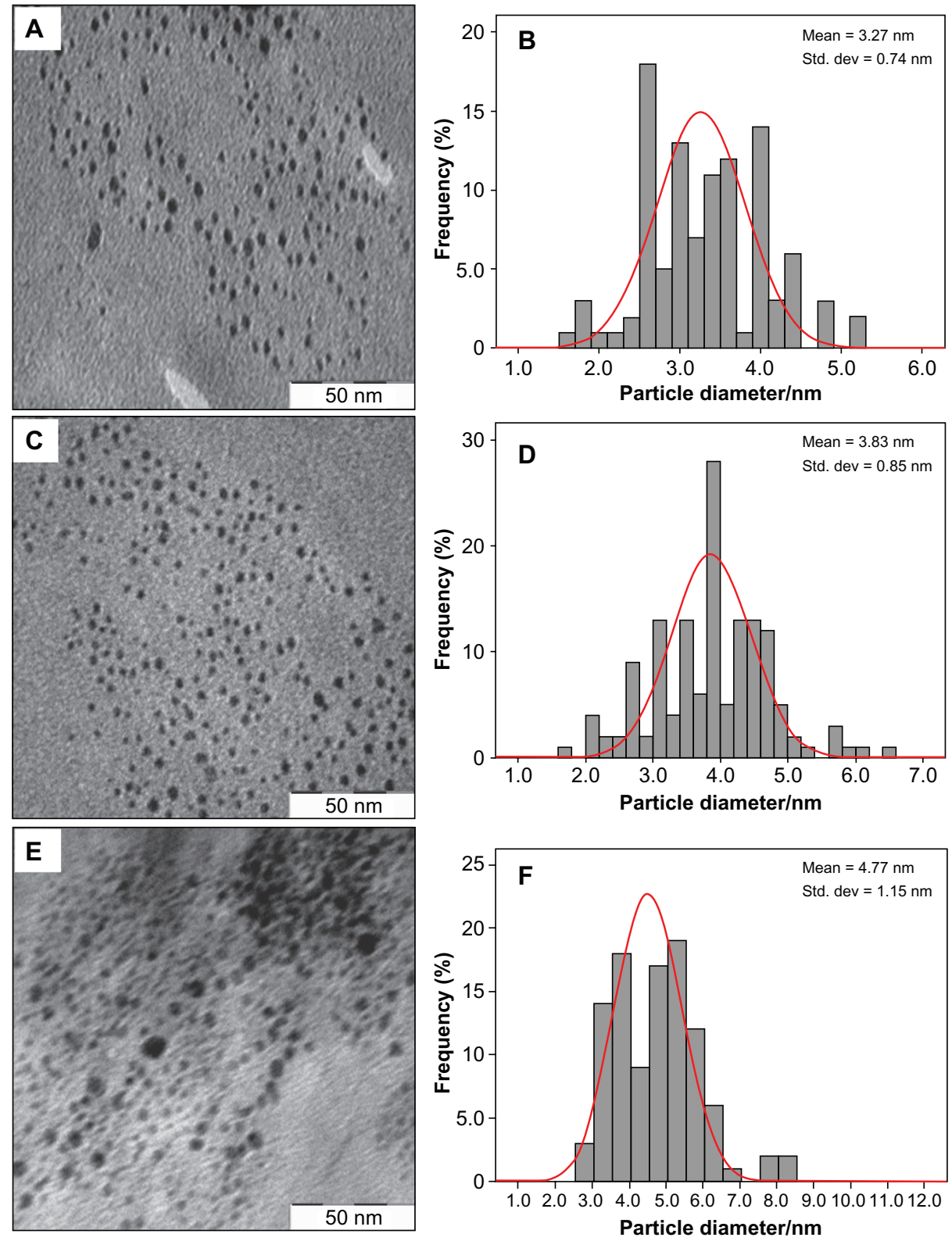

Figure 3 Transmission electron microscopy images and their corresponding size distributions of Ag/PLA-NCs at different Ag-NP percentages: 8 (A, B), 16 (C, D), and 32 wt\% (E, F).

Abbreviations: PLA-NC, poly (lactic acid) nanocomposite; Ag-NP, silver nanoparticle. 
polymeric matrix, particle diameters and standard deviation are increased.

\section{FT-IR chemical analysis}

FT-IR spectroscopy was used to characterize the interaction between the Ag-NPs with PLA. Figure 4 shows FT-IR peaks for PLA and Ag/PLA-NCs $(8,16$, and $32 \mathrm{wt} \%$ relative to PLA). The peaks at 1177 (1071), 2989 (2936), and $3502 \mathrm{~cm}^{-1}$ were assigned to the $\mathrm{C}-\mathrm{O}, \mathrm{C}-\mathrm{H}$ (double) and $\mathrm{O}-\mathrm{H}$ stretching of the $-\mathrm{CH}\left(\mathrm{CH}_{3}\right)-\mathrm{OH}$ end group of PLA, respectively. The splitting of the $\mathrm{C}=\mathrm{O}$ carbonyl stretching at ca. $1744 \mathrm{~cm}^{-1}$ might be due to the presence of $-\mathrm{CH}-\mathrm{CO}-\mathrm{O}-$ group. The peaks at 1448 , and $1356 \mathrm{~cm}^{-1}$ were assigned $-\mathrm{CH}_{3}$, and $-\mathrm{CH}-$ bending including symmetric and asymmetric bending. ${ }^{35,36}$ The interactions between PLA chain molecules and Ag-NPs are associated with the peak at $3493 \mathrm{~cm}^{-1}$. Broad peak is due to the presence of van der Waals interactions between the hydroxyl groups of PLA and the partial positive charge on the surface of the Ag-NPs. ${ }^{37}$

\section{Silver ion release}

Silver ions released from the Ag/PLA-NC films were investigated in PBS $(\mathrm{pH}=7.00)$. The released silver was detected using the atomic absorption spectroscopy, and it should be silver cations $\mathrm{Ag}^{+}$. Therefore, the metallic silver in the polymeric matrix was converted to cationic silver during the release process through reaction with water. As shown in Figure 5, the release of $\mathrm{Ag}^{+}$for a given silver content is relatively fast at the beginning, but it becomes slower according to incubation time, and the release can last for more than 18 days. The accumulative amount of silver ions released is dependent on the silver content in the polymeric films, whereby more initial silver content leads to a much faster release of $\mathrm{Ag}^{+}$. A steady and prolonged release of silver cations can inhibit the growth of bacteria when their concentrations are above $0.1 \mathrm{ppb}$. In the present study, the accumulative amount of the silver ions released could reach up to $60 \mathrm{ppm}$ of the polymeric films at the beginning stage of release. This suggests that Ag/PLA-NC films may have antibacterial ability.

\section{Antibacterial results}

Based on the results gathered from the agar disc diffusion test, all the Ag/PLA-NC films were found to exhibit a significant inhibition activity against $E$. coli ATCC 13706, S. aureus ATCC 12600, and V. parahaemolyticus ATCC 17802. The clear zones of the samples are shown in Table 1. Meanwhile, the inhibition zones surrounding the film square were formed, and these ranged from 1.43 to $10.33 \mathrm{~mm}$ against $E$. coli, from 4 to $15 \mathrm{~mm}$ against V. paraemolyicus, and from 4 to 9.3 against $S$. aureus, respectively, suggesting an antimicrobial activity of Ag/PLA-NCs. It is important to note that the antibacterial efficacies against Ag/PLA-NC films indicate that Ag-NPs are responsible for the antibacterial activity in

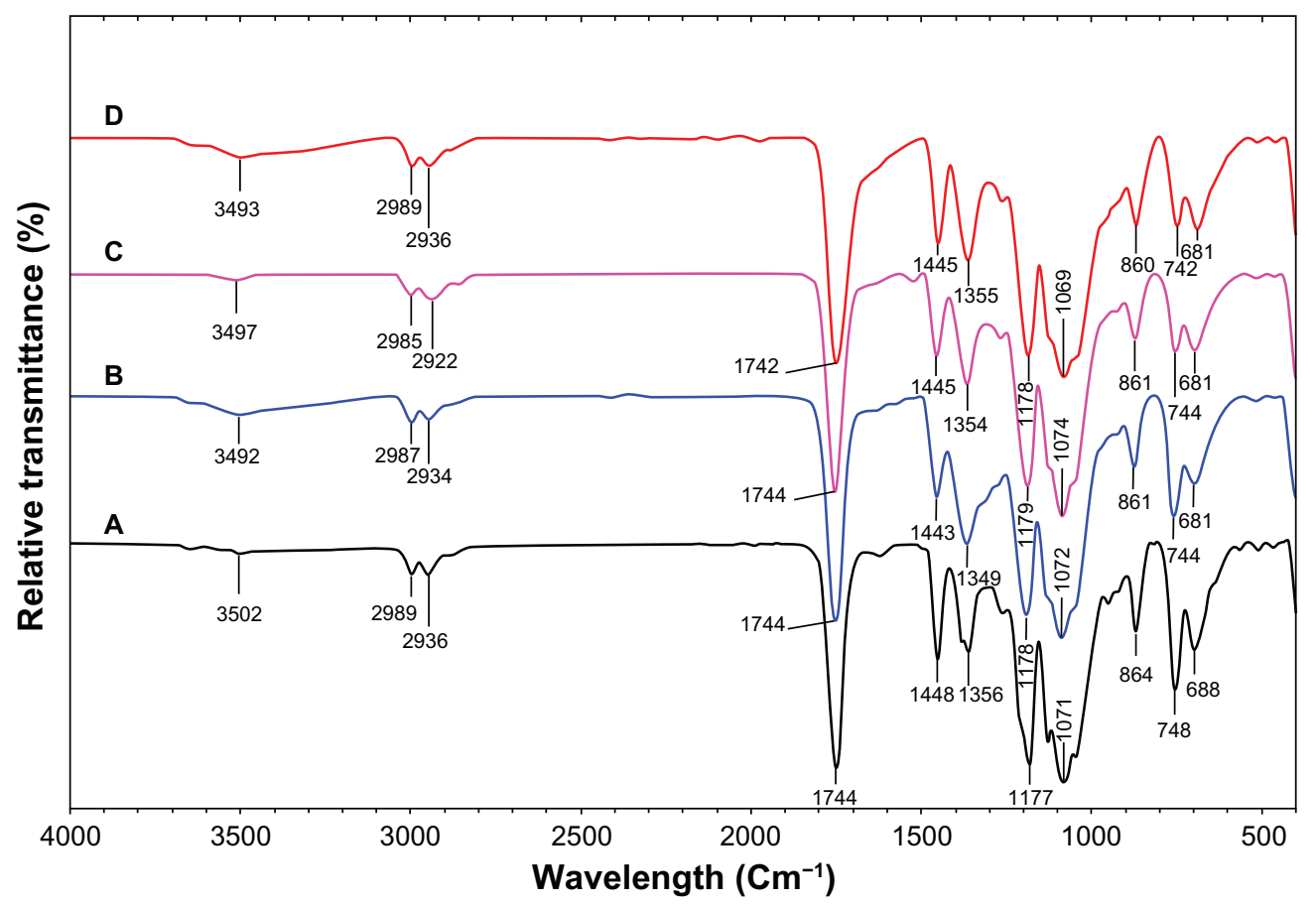

Figure 4 Fourier transform infrared spectra of PLA (A), Ag/PLA-NCs at 8 (B), 16 (C), 32 (D) wt\% Ag-NPs.

Abbreviations: PLA, poly (lactic acid); NC, nanocomposite; Ag-NP, silver nanoparticle. 


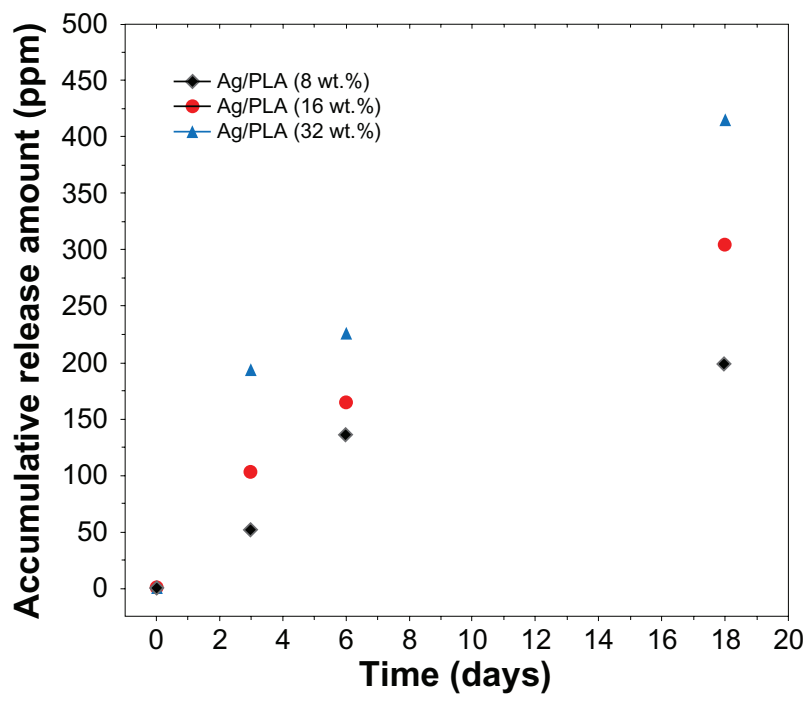

Figure $5 \mathrm{Ag}^{+}$release curves of $\mathrm{Ag} / \mathrm{PLA}-\mathrm{NCs}$ in $\mathrm{PBS}(\mathrm{pH}=7.00)$ with 8,16 , and 32 wt\% respectively.

Abbreviations: PLA, poly (lactic acid); NC, nanocomposite; PBS, phosphate buffer saline.

the polymer nanocomposites, and this activity is completely strong. The Ag-NPs are gradually released to $\mathrm{Ag}^{+}$, and thus, the antibacterial activity becomes tough. Similarly, the antibacterial efficacy against $V$. parahaemolyticus is more than the one against $E$. coli, and this is probably because of the difference in cell walls between the Gram-negative bacteria. These different behaviors are shown between $S$. aureus (as Gram-positive bacteria) and E. coli (as Gram-negative bacteria). The cell wall of E. coli, containing lipids, proteins, and lipopoly-saccharides (LPS) provides an effective protection against biocides. However, the cell wall of the Gram-positive bacteria, such as $S$. aureus, does not contain LPS. ${ }^{38}$ Figure 6 shows typical results of the tests carried out for the purpose of a first qualitative evaluation for V.parahaemolyticus; the antibacterial activity is evidenced by a zone of bacteria-growth inhibition, for the PLA and Ag/PLA-NC (8, 16, and $32 \mathrm{wt} \%)$ films. A similar inhibition zone is not present around the PLA film in Figure 6a, and there is bacteria growth also on the top of the sample. As expected, the most notable antibacterial

Table I Average of inhibition zones for PLA and Ag/PLA-NCs content 8, 16, and 32 wt\%

\begin{tabular}{llll}
\hline Bacteria & \multicolumn{3}{l}{ Inhibition zone $(\mathbf{m m})$} \\
\cline { 2 - 4 } Film samples & $\begin{array}{l}\text { Eschericha } \\
\text { coil }\end{array}$ & $\begin{array}{l}\text { Staphylococcus } \\
\text { aureus }\end{array}$ & $\begin{array}{l}\text { Vibrio } \\
\text { parahaemolyticus }\end{array}$ \\
\hline Control & - & 0.67 & - \\
Ag/PLA 8 wt\% & 1.43 & 4.00 & 4.00 \\
Ag/PLA 16 wt\% & 2.33 & 8.00 & 8.00 \\
Ag/PLA 32 wt\% & 10.33 & 9.33 & 15.00 \\
\hline
\end{tabular}

Abbreviations: PLA, poly (lactic acid); NC, nanocomposite.

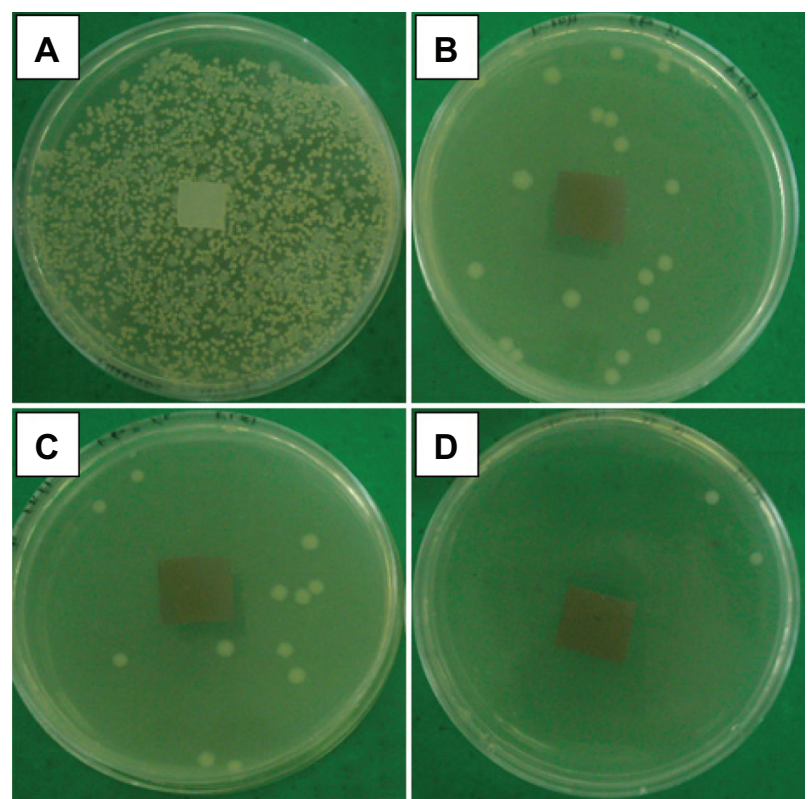

Figure 6 Comparison of inhibition zone test for Vibrio parahaemolyticus between PLA (A), Ag/PLA-NC content 8 (B), 16 (C), and 32 (D) wt\% respectively. Abbreviations: PLA, poly (lactic acid); NC, nanocomposite.

effect is observed for the Ag/PLA-NCs (32 wt \%) with the highest percentage (Figure 6d); reduced antibacterial effect are noted in Figures $6 \mathrm{~b}$ and $6 \mathrm{c}$ respectively.

\section{Conclusion}

A simple way to prepare uniform size of Ag-NPs in PLA by reacting different percentages of nanoparticles in PLA with sodium borohydride as reducing agent was developed. The average diameters of the Ag-NPs were between 3.27, 3.83, and $4.77 \mathrm{~nm}$ with well crystallized structures, and Ag-NP diameters increase with increasing amount of $\mathrm{AgNO}_{3}$ added. XRD analysis confirms that crystallographic planes of the silver crystal are the fcc types. UV-vis absorption spectra show peaks characteristic of the surface plasmon resonance of Ag-NPs. FT-IR shows that interactions exist between molecules of PLA and Ag-NPs. The antibacterial activity of Ag/PLA-NC films was demonstrated and showed a strong antibacterial activity against Gram-negative and Gram-positive bacteria. Further studies investigate the bactericidal effect of Ag/PLA-NC films on the types of bacteria for potentially widening such wound dressings or as anti-adhesion membranes.

\section{Acknowledgments}

Thanks are due to Professor Abdolhossein Rustaiyan and Mrs Parvaneh Shabanzadeh for helpful discussions and in giving the authors the idea. The authors are also grateful to the Institute of Bioscience (IBS/UPM) and Mrs A Jusoh in the TEM unit for technical assistance in this project. 


\section{Disclosure}

The authors have no conflicts of interest to disclose in this work.

\section{References}

1. Ikada Y, Tsuji H. Biodegradable polyesters for medical and ecological applications. Macromol Rapid Comm. 2000;2:117-132.

2. Jain RA. The manufacturing techniques of various drug loaded biodegradable poly (lactide-co-glycolide) (PLGA) devices. Biomaterials. 2000;2:2475-2490.

3. Mikos A, Lyman M, Freed L, et al. Wetting of poly (L-lactic acid) and poly (D, L-lactic-co-glycolic acid) foams for tissue culture. Biomaterials. 1994;15:55-58.

4. Taylor MS, Daniels AU, Andriano KP, et al. Six bioabsorbable polymers: in vitro acute toxicity of accumulated degradation products. J Appl Biomater. 1994;5(2):151-157.

5. Park T, Cohen S, Langer R. Poly (L-lactic acid)/pluronic blends: characterization of phase separation behavior, degradation, morphology and as protein releasing matrices. Macromolecules. 1992;25:116-122.

6. Tsuji H, Ikada Y. Blends of aliphatic polyesters. II. hydrolysis of solution-cast blends from poly (L-lactide) and poly (E-caprolactone) in phosphate-buffered solution. J Appl Polym Sci. 1998;67:405-415.

7. Urayama H, Kanamori T, Kimura Y. Properties and biodegradability of polymer blends of poly (L-lactide) with different optical purity of the lactate units. Macromol Mater Eng. 2002;287:116-121.

8. Iwata T, Doi Y. Morphology and enzymatic degradation of poly (L-lactic acid) single crystals. Macromolecules. 1998;31:2461-2467.

9. Sinclair RG. The case for polylactic acid as a commodity packaging plastic. J Macromol Sci. 1996;33:585-597.

10. Sawai D, Takahashi K, Imamura T, et al. Preparation of oriented $\beta$-form poly (L-lactic acid) by solid-state extrusion. Polym Sci Poly Phys Ed. 2002;40:95-104.

11. Novikova LN, Novikov LN, Kellerth JO. Biopolymers and biodegradable smart implants for tissue regeneration after spinal cord injury. Curr Opin Neurol. 2003;16:711-715.

12. Vito C, Quatela MD, Jen CMD. Facial plastic surgery clinics of North America. Synthetic Facial Implants. 2008;16:1-10.

13. Chen Y, Mak AFT, Wang M, et al. PLLA scaffolds with biomimetic apatite coating and biomimetic apatite/collagen composite coating to enhance osteoblastlike cells attachment and activity. Surface Coatings Technol. 2006;201:575-580.

14. Park KE, Kang HK, Lee SJ, et al. Biomimetic nanofibrous scaffolds: preparation and characterization of PGA/Chitin blend nanofibers. Biomacromolecules. 2006; 7:635-643.

15. Chen X, Schluesener HJ. Nanosilver: a nanoproduct in medical application. Toxicol Lett. 2008;176:1-12.

16. Alt V, Bechert T, Steinrücke P, et al. An in vitro assessment of the antibacterial properties and cytotoxicity of nanoparticulate silver bone cement. Biomaterials. 2004;25:4383-4391.

17. Shan B, CaiYZ, Brooks JD, et al. Antibacterial properties of polygonum cuspidatum roots and their major bioactive constituents. Food Chem. 2008;109:530-537.

18. Li Y, Leung P, Yao L, et al. Antimicrobial effect of surgical masks coated with Nanoparticles. J Hosp Infect. 2006;62:58-63.
19. Yeo SY, Lee HJ, Jeong SH. Preparation of nanocomposite fibers for permanent antibacterial effect. J Materials Sci. 2003;38: 2143-2147.

20. Zheng M, Gu M, Jin Y, et al. Optical properties of silver-dispersed PVP thin film. Mater Res Bull. 2001;36:853-859.

21. Khanna PK, Singh N, Charan S, et al. Synthesis and characterization of Ag/PVA nanocomposites by chemical reduction method. Mater Chem Phys. 2005;93:117-121.

22. Lu HW, Liu SH, Wang XL, et al. Silver nanocrystals by hyperbranched polyurethane assisted photochemical reduction of $\mathrm{Ag}^{+}$. Mater Chem Phys. 2003;81:104-107.

23. Zhang Z, Zhang L, Wang S, et al. A convenient route to polyacrylonitrile/silver nanoparticle composite by simultaneous polymerization-reduction approach. Polymer. 2001;42:8315-8318.

24. Adlim M, Abu Bakar M, Liew KW, et al. Synthesis of chitosanstabilized platinum and palladium nanoparticles and their hydrogenation activity. J Mol Catal A: Chem. 2004;212:141-149.

25. Raveendran P, Fu J, Wallen SL. Completely "green" synthesis and stabilization of metal nanoparticles. J Am Chem Soc. 2003;125: 13940-13941.

26. Kotelnikova NE, Wegener G, Stoll M, et al. Comparative study of intercalation of zero-valent silver into the cellulose matrix by raster and transmission microscopy. Chem Polym Mater. 2003;76: $117-123$.

27. Appendini P, Hotchkiss JH. Review of antimicrobial food packaging. Innov Food Sci Emerg Technol. 2002;3:113-126.

28. Turkevich J, Stevenson PC, Hillier J. The nucleation and growth processes in the synthesis of colloidal gold. Disc Faraday Soc. 1951;11: $55-75$.

29. Roucoux A, Schulz J, Patin H. Reduced transition metal colloids: a novel family of reusable catalysts. Chem Rev. 2002;102:3757-3778.

30. Temgire MK, Joshi SS. Optical and structural studies of silver nanoparticles. Radiat Phys Chem. 2004;71:1039-1044.

31. Prasad V, Souza CD, Yadav D, et al. Spectroscopic characterization of zinc oxide nanorods synthesized by solid-state reaction. Spectrochim Acta A. 2006;65:173-178.

32. Aihara N, Torigoe K, Esumi K. Preparation and characterization of gold and silver nanoparticles in layered laponite suspensions. Langmuir. 1998;14:4945-4949.

33. Lin XZ, Teng X, Yang H. Direct synthesis of narrowly dispersed silver nanoparticles using a single-source precursor. Langmuir. 2003;19: 10081-10085.

34. Ahmad MB, Shameli K, Darroudi M, et al. Antibacterial activity of silver/clay/chitosan bionanocomposites. Res J Biol Sci. 2009;4(11): 1156-1161.

35. Younes H, Cohn D. Phase separation in poly (ethylene glycol)/poly (lactic acid) blends. Eur Polym J. 1988;24:765-773.

36. Agarwal M, Koelling KW, Chalmers JJ. Characterization of the degradation of poly-lactic acid in a well-controlled composting system. Biotechnol Progr. 1998;14:517-526.

37. Da Silva EC, Da Silva MGA, Meneghetti SMP, et al. Synthesis of colloids based on gold nanoparticles dispersed in castor oil. J Nanopart Res. 2008;10:201-208.

38. Speranza G, Gottardi G, Pederzolli C, et al. Role of chemical interactions in bacterial adhesion to polymer surfaces. Biomaterials. 2004;25:2029-2037.

International Journal of Nanomedicine

\section{Publish your work in this journal}

The International Journal of Nanomedicine is an international, peerreviewed journal focusing on the application of nanotechnology in diagnostics, therapeutics, and drug delivery systems throughout the biomedical field. This journal is indexed on PubMed Central, MedLine, CAS, SciSearch $\AA$, Current Contents ${ }^{\circledR} /$ Clinical Medicine,

\section{Dovepress}

Journal Citation Reports/Science Edition, EMBase, Scopus and the Elsevier Bibliographic databases. The manuscript management system is completely online and includes a very quick and fair peer-review system, which is all easy to use. Visit http://www.dovepress.com/ testimonials.php to read real quotes from published authors. 